Meta

Journal des traducteurs

Translators' Journal

\title{
Construction of a Biomedical Nomenclature
}

\section{Elmer R. Gabrieli}

Volume 31, numéro 1, mars 1986

Traduction et terminologie médicale

Medical Translation and Terminology

URI : https://id.erudit.org/iderudit/002780ar

DOI : https://doi.org/10.7202/002780ar

Aller au sommaire du numéro

Éditeur(s)

Les Presses de l'Université de Montréal

ISSN

0026-0452 (imprimé)

1492-1421 (numérique)

Découvrir la revue

Citer cet article

Gabrieli, E. R. (1986). Construction of a Biomedical Nomenclature. Meta, 31(1),

22-25. https://doi.org/10.7202/002780ar d'utilisation que vous pouvez consulter en ligne.

https://apropos.erudit.org/fr/usagers/politique-dutilisation/ 


\section{CONSTRUCTION OF A BIOMEDICAL NOMENCLATURE}

When a patient is discharged from the hospital, the attending physician must summarize the entire clinical event using a few words. The list of diagnoses, and when applicable, the surgeries performed are those few words. The physician is aware of the importance of this case summary, and chooses the diagnostic terms with great care. These summarizing date are used for many purposes. The patient's subsequent followup treatment is guided by the diagnoses established in the hospital. These diagnoses are the information carriers between the hospital-based physician and the doctor providing the subsequent care. The insurance carrier pays the hospital, and the physician, according to the diagnosis and the surgery performed. Biostaticians monitor the discharge diagnoses to observe national or regional trends of diseases, to detect outbreaks of diseases, and to assess the effectiveness of clinical medicine in various disease categories. Quality control studies focus on the quality of the medical care given. These are now mandatory in all U.S. hospitals. Again, the point of reference is the diagnosis.

The medical diagnoses and the names of surgical procedures are the primary information carriers in all medical communications ranging from patient records to clinical consultations and medical literature. The medical language consists of medical terms. It seems quite important that the medical terminology should be explicit, wellstandardized, with sharply defined meaning, in order to achieve accurate communication among physicians. Unfortunately, the current status of the medical nomenclature, in the United States, (and throughout the world) does not meet these requirements. Owing to the rapid progress in all fronts of medicine, new names are constructed daily by researchers, without any coordination. Teachers at medical schools often choose their own preferred terms when alternative expressions are available. Consequently, physicians trained in California may call a disease different from those educated in Boston or New York.

Computers enable us to compare large numbers of clinical cases so that we can draw important statistical conclusions. However, in order to create large case history databanks, the names of diseases and surgical operations should be uniformly used by all physicians. This calls for a large-scale standardization of the medical nomenclature.

During the last few years, there were several conferences held ${ }^{1}$ focusing on the need for a standard medical nomenclature. The result of these conferences was that in May, 1985, a group of interested physicians met with ASTM, a major standardization organization, and agreed to launch a program for constructing a modern, comprehensive, accurate medical nomenclature. The purpose of this paper is to describe the basic rules considered by the architects of this new medical nomenclature.

\section{BRIEF HISTORY OF MEDICAL NOMENCLATURE}

The first purposeful attempt to enumerate the cause of death in children was the "London Bill of Mortality", in 1770, listing 13 major causes ${ }^{2}$. These 13 categories represented 36 per cent of all the deaths of live-born children. It may be of historic interest to list these frequent causes of death : thrush, convulsions, rickets, teeth and worms, abortiveness, chrysomes, infants liver grown, overlaid, small pox, swine pox, measles and worms without convulsions. These diagnoses reflect the stage of medicine in 1700, with 
an obvious lack of specificity. Nevertheless, it is interesting that this document listed "overlaid", a diagnosis which is still a puzzle to pediatrics, although the name has been changed. Today, it is called "sudden infant death syndrome".

As medicine progressed, the list of fatal diseases increased. Consequently, the accuracy of the terminology kept improving. François Bossier de Lacroix (1706-1777) compiled the first purposeful "Nosologia Methodica" in the late 1700s, and William Cullen of Edinburgh (1710-1790) organized the first truly scientific medical nomenclature, the "Synopsis Nosolgiae Methodicae" in 1785.

The truly modern approach to disease classification began in the $1800 \mathrm{~s}$. William Farr, (1807-1883) the Registrar General for England Wales ${ }^{3}$ showed remarkable clinical insight when he created five main disease categories : epidemic diseases, general diseases, local diseases ordered by anatomic site, developmental disorders and diseases resulting from violence. Under these five category headings, Farr listed 139 specific diseases. In the first Annual Report of the Registrar General, Farr wrote the much quoted comment :

Each disease has, in many instances, been denoted by three or four terms, and each term has been applied to as many different diseases : vague, inconvenient names have been employed, or complications have been registered instead of primary diseases. The nomenclature is of as much importance in this department of inquiry as weights and measures in the physical sciences, and should be settled without delay.

The importance of standard terminology was fully recognized by the first International Statistical Congress in Brussels, in 1853. William Farr and Marc d'Espine of Geneva were requested to prepare "une nomenclature uniforme des causes de décès applicable à tous les pays. Farr showed remarkable insight when he introduced the principle of classifying diseases by anatomical site. This is still the prevailing key for classification of diseases.

In 1891, Jacques Bertillon (1851-1922) became the chairman of the committee for classification of diseases. Bertillon was the grandson of Achille Gilliard, a prominent botanist who had introduced the famous resolution in 1853, at the First Statistical Congress, requesting Farr and d'Espine to draft a uniform classification.

Farr is considered by medical historians as the author of the first truly scientific disease classification scheme, but the subsequent work by Jacques Bertillon is viewed by many as the foundation of our current disease classification. An important step was the recommendation of the American Public Health Association in 1898 that the Bertillon classificaiton scheme be used throughout the Western hemisphere, and that this listing be revised every ten years. This recommendation was the needed stimulus for a formal systematization of diseases.

After Bertillon's death, in 1922, the Health Organization of the League of Nations took over the responsibility of sponsoring the regular publication of the tabulation of diseases as causes of death. In 1946, the World Health Organization accepted the responsibility to continue with the "International Classification of Diseases". The latest version of this listing was published in $1975^{4}$.

Reflecting the mission of the World Health Organization, the purpose of the International Classification of Diseases was to create a limited number of disease categories which can be used to derive statistical inferences. The latest version of the International Classification of Diseases lists 17000 such categories. However, this categorization is at the expense of the precision. In a sense, the purpose of the International Classification of Diseases is diametrically opposite to that of the physician. The latter strives for greater and greater accuracy, whereas the former wants to suppress 
finer differences, in order to create categories with sufficient members in each, for statistical comparisons.

In the United States, the New York Academy of Medicine initiated a conference in 1928 , to create a "logical clinical nomenclature"5. The basic plan for the new medical nomenclature was completed by 1930 , and the first printing appeared in 1932 . The American Medical Association accepted the responsibility to maintain the Standard Nomenclature of Diseases and Operations. The basic plan of this scheme was a dual coding : one code defined the site of the disease, (liver, kidney, etc.) and the second the cause of the disease. The excellent design of the Standard Nomenclature of Diseases and Operations resulted in a practical, accurate nomenclature, eminently suited for coding medical diagnoses and procedures. Unfortunately, the logic of the system became obsolete quite rapidly. Medicine discovered that certain clinical conditions can be due to several causes, and that a single disease may involve several organs. In 1961 the editors of the last version ${ }^{6}$ declared that the basic design had become irreversibly obsolete, and terminated the project.

During the period after the Standard Nomenclature of Diseases and Operations, numerous efforts were made by various medical specialty groups to create thesauri for their own use. The systematized Nomenclature of Pathology ${ }^{7}$ in 1965 , the terminology of obstetrics ${ }^{8}$ of psychiatry ${ }^{9}$ are some of the examples. There was an attempt to build a comprehensive medical nomenclature ${ }^{10}$ but the product was not accepted by clinical medicine.

In the 1970s, when the United States Congress decided that the Government should finance the health care for the elderly, a nomenclature was required for reimbursement purposes. Unfortunately, the only listing of diseases and procedures which was kept current was the International Classification of Diseases. This scheme was made the official nomenclature of clinical medicine in the U.S., despite its recognized numerous shortcomings as a medical nomenclature.

\section{CURRENT PLANS FOR A MEDICAL NOMENCLATURE}

The evolving medical nomenclature project is considering the following suggestions :

\section{A. SPECIFIC OBJECTIVES}

First, one must delineate the exact dimensions of the task. In this project, medical terms are those recognized, widely used expressions which represent discrete biomedical concepts. Medical terminology is the collection of such medical terms. Medical nomenclature is larger in scope : a systematized presentation of the medical terms, arranged by their meaning, and ordered into a classification scheme. The dictionary of biomedical terms is even more : a listing of medical terms, along with the definition of the meaning of each term. The lexicon of nomenclature is the most comprehensive arrangement : medical terms-cum-definition taxonomically arranged. The most ambitious goal is the medical encyclopedia : the fully organized knowledge base of medicine. The specific objective of our project will be limited to the construction of comprehensive and accurate medical nomenclature.

\section{B. DEFINITION OF USERS}

The standard nomenclature should meet the needs of clinical medicine as well as the needs of all segments of the health care industry, the insurance industry, the research community, the educational system, and last but not least the requirements of the computer systems. Further, there should be "crosswalks" (i.e., compatibility with all the currently existing terminology systems) to assure a smooth transition. 


\section{SYSTEM CONCEPT}

Medical nomenclature is viewed as a cohesive concept, an all-inclusive, semantically organized body of medical terms. Instead of the proliferating clinical specialty thesauri (systematized vocabularies of limited subjects) such as one for psychiatry, one for arthritis, one for diabetes, and so on, an integrated terminology system should eliminate the current artificial communication boundries among clinical specialties. This calls for a consensus by all specialty areas.

\section{PREFERRED TERMS}

When multiple synonymous expressions are in use, judicious choice of the preferred term must be made by the clinical experts involved. The nomenclature should list the preferred terms, whereas the synonyms should be subordinated to the preferred term.

The preferred terms should be unique in the nomenclature. One concept should be represented by only one preferred term, and there should be only one representation for each medical concept.

\section{E. RESOLVING POWER OF THE NOMENCLATURE}

The medical nomenclature consists of two types of terms : class terms such as "anemia" or "hepatitis" which are amalgamations of several different, discrete concepts, and terminal terms (root concepts) which, according to the present state-of-the-art, are no longer divisible with special regard to their diagnostic, prognostic, therapeutic and epidemiologic aspects.

Class terms should be divided until the terminal terms are encountered. Careful clinical judgment must be exercised to avoid the creation of artifacts (i.e., split terms) which are no longer representations of discrete concepts. The resolving power of the nomenclature should be equal to the current clinical perception of concepts and real-life clinical entities.

\section{LONG-RANGE PLANS}

Although the current efforts are focused on the development of a North American standard medical nomenclature, the participants are aware of the possibility that this nomenclature will probably be adopted world-wide. If the medical terms would be reduced to simple numeric codes, these codes could be used around the world as representations of well-defined medical concepts.

\section{References}

1. Transactions of the Howard University Conference, Journal of Clinical Computing, vol. 12-1,2, 1983.

2. GANTNER, George E. (1977) : "Medical Linguistics and the Computer", Manual of International School on Foundations of Medical Informatics, Florence, Italy, International Menerini Foundation.

3. Registrar General of England and Wales: First Annual Report, 1839, p. 99.

4. Eighth Revision International Classification of Diseases, U.S. Department Health, Education, and Welfare, Public Health Service Publication, No 1693, p. xiii, 1965.

5. Standard Nomenclature of Diseases and Operations; Fifth Edition, Published for the American Medical Association, McGraw-Hill Book Company, 1961.

6. Ibid.

7. Systematized Nomenclature of Pathology, College of American Pathologists, Chicago, Illinois, 1965.

8. Obstetric-Gynecologic Terminology, The American College of Obstetricians and Gynecologists, Edward C. Hughes, Editor, F.A. Davis Company.

9. A Psychiatric Glossary, Fourth Edition, American Psychiatric Association, Washington, D.C., 1975.

10. College of American Pathologists (1955) : Systematized Nomenclature of Medicine (SNOMED), Second Edition, 2 Volumes, Skokie, Illinois. 